\title{
DEGRADAÇÃO MECÂNICA DE PELOTAS DE MINÉRIO DE FERRO DURANTE O MANUSEIO E TRANSPORTE. PARTE 1: MODELO MATEMÁTICO E SIMULADOR*
}

\section{Resumo}

Luís Marcelo Marques Tavares ${ }^{1}$ Rodrigo Magalhães de Carvalho ${ }^{2}$ Marcus Winitskowski da Silveira ${ }^{3}$ Hélio Cardoso Pereira ${ }^{4}$

Maciel Rodrigues Bianchi ${ }^{5}$

Maurício Marcos Otaviano 6 Bruno Cezar Evaristo Pereira ${ }^{7}$

Pelotas de minério de ferro representam uma parcela significativa do mercado transoceânico de minério de ferro, contando com uma participação importante de empresas brasileiras. Pelotas concorrem favoravelmente com granulados e sínteres de minério de ferro na carga metálica de fornos, em particular devido à sua elevada resistência à degradação durante o manuseio e transporte. Entretanto, pelotas ainda sofrem desse problema, que resulta na geração de finos, removidos previamente à alimentação do forno, ou de cacos, que podem resultar no aparecimento de clusters em fornos de redução direta. Esses efeitos danosos da degradação podem ser minimizados caso uma metodologia adequada de caracterização de pelotas e de simulação do processo de manuseio se encontrasse disponível. O presente trabalho trata do desenvolvimento de metodologia inédita e inovadora para previsão de resultados de degradação de pelotas, desde a usina pelotizadora até o pátio ou forno do cliente, desenvolvido como parte da parceria entre o Laboratório de Tecnologia Mineral da COPPE/UFRJ e a Samarco Mineração. O trabalho mostra ainda uma validação preliminar a partir de um ensaio de quedas múltiplas em laboratório, mostrando ótima aderência. Um simulador do processo foi desenvolvido, o qual permite inserir as características das pelotas produzidas, bem como o fluxograma de manuseio, permitindo prever a intensidade da degradação.

Palavras-chave: Pelotas; Minério de ferro; Degradação; Simulação; Manuseio.

\section{MECHANICAL DEGRADATION OF IRON ORE PELLETS DURING HANDLING. PART 1: MATHEMATICAL MODEL AND SIMULATOR}

\section{Abstract}

Iron ore pellets represent a significant proportion of the transoceanic market of iron ore, in which companies that operate in Brazil represent an important part. Pellets compete favorably with lump iron ore and sinter in the metallic charge in furnaces, in particular because of their high resistance to degradation during handling and transportation. However, pellets still suffer from this problem, which results in the generation of fines, which are removed before feeding the furnace, or fragments, which can result in the appearance of clusters in the direct reduction furnace. These damaging effects of degradation could be addressed if a proper methodology for pellets and a simulator were available. The present work deals with the development of a novel and innovative methodology for predicting results from pellet degradation, from the pelletizing plant to the steel mill. It was developed as part of a collaboration between the Laboratório de Tecnologia Mineral from COPPE/UFRJ and Samarco Mineração. The work also shows a preliminary validation of the model made on the basis of multiple drop tests conducted in the laboratory, showing very good agreement. A process simulator was developed, which allows inserting the characteristics of the pellets produced, as well the handling flowsheet, allowing to predict the intensity of degradation that will occur in practice.

Keywords: Pellets; Iron ore; Degradation; Simulation; Handling.

${ }^{1}$ Eng. de Minas, M.Sc., Ph.D, Prof. Titular, Programa de Eng. Metalúrgica e de Materiais, COPPE, UFRJ, Rio de Janeiro, RJ, Brasil.

2 Eng. Químico, M.Sc., D.Sc., Prof. Adjunto, Programa de Eng. Metalúrgica e de Materiais, COPPE, UFRJ, Rio de Janeiro, RJ, Brasil.

${ }^{3}$ Eng. Metalúrgico, M.Sc., Pesquisador Auxiliar, Laboratório de Tecnologia Mineral, COPPE, UFRJ, Rio de Janeiro, RJ, Brasil.

${ }^{4}$ Eng. Metalúrgico, M.Sc., Especialista de Produto Sênior, Gerencia Geral de Marketing; Samarco Mineração S/A, ES, Brasil.

${ }^{5}$ Eng. Metalúrgico, Analista de Produtos, Gerencia de Relacionamento com o Mercado, Samarco Mineração S/A, ES, Brasil.

${ }^{6}$ Eng. Metalúrgico, D.Sc., Especialista de Produtos Senior, Gerencia Geral de Marketing; Samarco Mineração S/A, ES, Brasil.

${ }^{7}$ Eng. Metalúrgico, Analista de Produtos, Gerencia de Relacionamento com o Mercado, Samarco Mineração S/A, ES, Brasil. 


\section{INTRODUÇÃO}

Pelotas de minério de ferro representam uma parcela significativa do mercado transoceânico de minério de ferro, contando com uma participação importante de empresas brasileiras. Pelotas correspondem quase à totalidade da carga metálica de fornos de redução direta, participando também da carga de altos fornos.

Pelotas concorrem com granulados na carga metálica nos processos de redução direita e com sinteres e granulados na rota de alto fornos, apresentando vantagens sobre seus concorrentes no que diz respeito a alguns quesitos importantes, incluindo a maior regularidade na distribuição granulométrica e constância na qualidade química, bem como a boa redutibilidade [1]. No entanto, uma das principais vantagens de pelotas em relação aos seus concorrentes é a sua resistência superior à degradação mecânica, tanto durante o manuseio e transporte, quanto durante a redução no interior dos fornos. Essas vantagens contribuem para melhorar a estabilidade operacional dos fornos, resultando em ganhos de redutibilidade e produtividade, tornando pelotas atrativas para as duas rotas de produção de ferro primário.

Ainda que apresentem maior resistência à degradação mecânica, pelotas são susceptíveis a este fenômeno, embora em menor magnitude que granulados e sínteres. A degradação ocorre principalmente durante a etapa de manuseio, na qual finos (partículas com tamanhos menores que, tipicamente, $5 \mathrm{~mm}$ ) podem ser gerados, os quais são removidos da alimentação dos fornos por peneiramento e vendidos a custos marginais por siderúrgicas que não dispõem de unidades de sinterização. Adicionalmente, a degradação durante o manuseio também pode ser responsável pela geração de cacos, ou seja, partículas com tamanhos superiores a, aproximadamente, $5 \mathrm{~mm}$, mas que correspondem a fragmentos de pelotas. Como não são removidos por peneiramento, esses cacos são alimentados aos fornos, podendo, no caso do processo de redução direta, contribuir para a formação de cachos ou clusters [2]. A presença desses cachos no interior dos fornos é prejudicial para a permeabilidade dos gases, podendo comprometer 0 desempenho do processo de redução [3].

Diversas são as variáveis que influenciam a degradação de pelotas durante o manuseio. Elas podem ser classificadas entre aquelas que dependem das características intrínsecas das pelotas produzidas e aquelas que dependem dos processos de manuseio aos quais elas são submetidas desde a usina de pelotização até os fornos de redução Dentre as variáveis que influenciam diretamente na resistência mecânica de pelotas estão a composição mineralógica do pellet feed, as características dos aditivos empregados, o método usado na formação de pelotas, a distribuição granulométrica , bem como as condições de queima empregadas no forno de endurecimento, entre outras [1,4-6]. Por outro lado, a degradação pode ser tão maior quanto mais intensos forem os esforços mecânicos aos quais as pelotas são submetidas. Esses esforços podem variar desde quedas em chutes de transferência entre transportadores de correia, métodos de empilhamento e carregamento e descarga para o transporte até o consumidor final.

Assim, seria muito importante que a empresa pelotizadora dispusesse de meios de prever, com alto grau de confiança, a intensidade da degradação sofrida por cada tipo de pelota produzida e em função da severidade do processo de manuseio que serão submetidas. A partir desse conhecimento, a empresa seria capaz de melhor orientar esforços de engenharia no sentido de minimizar o efeito deste fenômeno como: a formulação e controle de processo para desenvolvimento de pelotas com 
características diferenciadas; adequação do programa de manutenção de equipamentos de processo e melhorias nos diversos sistemas de transporte, tendo em vista a redução da variabilidade de paramentos críticos para a degradação, assim como aconselhar o cliente quando a possiblidades de melhorias de seus sistemas.

As normas e metodologias internacionais, utilizadas para as interfaces comerciais, disponíveis para caracterização do produto final, têm como objetivo medir propriedades e parâmetros do produto e não simular os esforços sofridos em diferentes possibilidades de manuseio. Assim, tendo em vista a falta de métodos para simulação da degradação mecânica de pelotas, bem como a indisponibilidade de modelos matemáticos adequados, foi desenvolvido um projeto conjunto empresauniversidade (Samarco Mineração/Laboratório de Tecnologia Mineral da COPPE/UFRJ) com o propósito de desenvolver uma solução integrada para o problema. O projeto, iniciado em 2009, compreendeu quatro componentes principais:

a. Proposição de novas metodologias de ensaio para caracterização de pelotas com vistas à medida de propriedades relevantes para o manuseio;

b. Desenvolvimento de modelos matemáticos capazes de simular os esforços mecânicos envolvidos nas diferentes etapas de manuseio;

c. Desenvolvimento de um simulador de processos, a fim de prever a proporção de finos e cacos (fragmentos) formados desde a usina pelotizadora até o pátio do cliente;

d. Implantação de novas metodologias experimentais para caracterização de pelotas no laboratório de ensaios da empresa pelotizadora.

O presente trabalho apresenta, de forma sucinta, o desenvolvimento dessa metodologia inovadora, focando os itens a-c listados acima.

\section{DESENVOLVIMENTO DO MODELO MATEMÁTICO E DO SIMULADOR DE DEGRADAÇÃO}

O modelo, baseado no modelo originalmente desenvolvido para granulados de minério de ferro [7], foi concebido com o objetivo de discriminar explicitamente tanto as contribuições provenientes das características das pelotas quanto do processo de manuseio, incluindo operações como retomadas, quedas, transferências, etc, na degradação mecânica. A estrutura básica do modelo é ilustrada na Figura 1, que mostra as diferentes contribuições do processo de manuseio e do material na degradação resultante.

O modelo se caracteriza por distinguir os diferentes mecanismos de fratura (quebra) envolvidos na degradação de minérios em função da magnitude da energia de impacto aplicada ao material, permitindo prever a proporção de partículas quebradas e a distribuição granulométrica resultante, em uma sequência qualquer de eventos de impacto.

Sabe-se que nem sempre uma partícula fratura após um impacto a uma determinada energia. Nesse caso, a superfície da partícula sofre uma pequena perda de massa (normalmente denominada "abrasão" ou "lascamento") e a partícula acumula dano na forma de uma ou mais trincas, ou na propagação daquelas já existentes. Dessa maneira, a partícula poderá vir a fraturar catastroficamente num impacto seguinte de menor magnitude. Essa degradação pode ser interpretada à luz de uma abordagem mecanicista, através do enfraquecimento progressivo da partícula, resultante dos impactos repetidos que ela sofre durante o seu processo de 
manuseio. O modelo utilizado no presente trabalho baseia-se na combinação da mecânica do dano com a teoria de contatos elásticos de Hertz na descrição do impacto de uma partícula [8]. A aplicação do modelo é dada pela mudança do comportamento mecânico da partícula, representado por uma curva de força versus deformação que varia como consequência de sucessivos impactos de mesma magnitude, conforme ilustra a Figura 2.

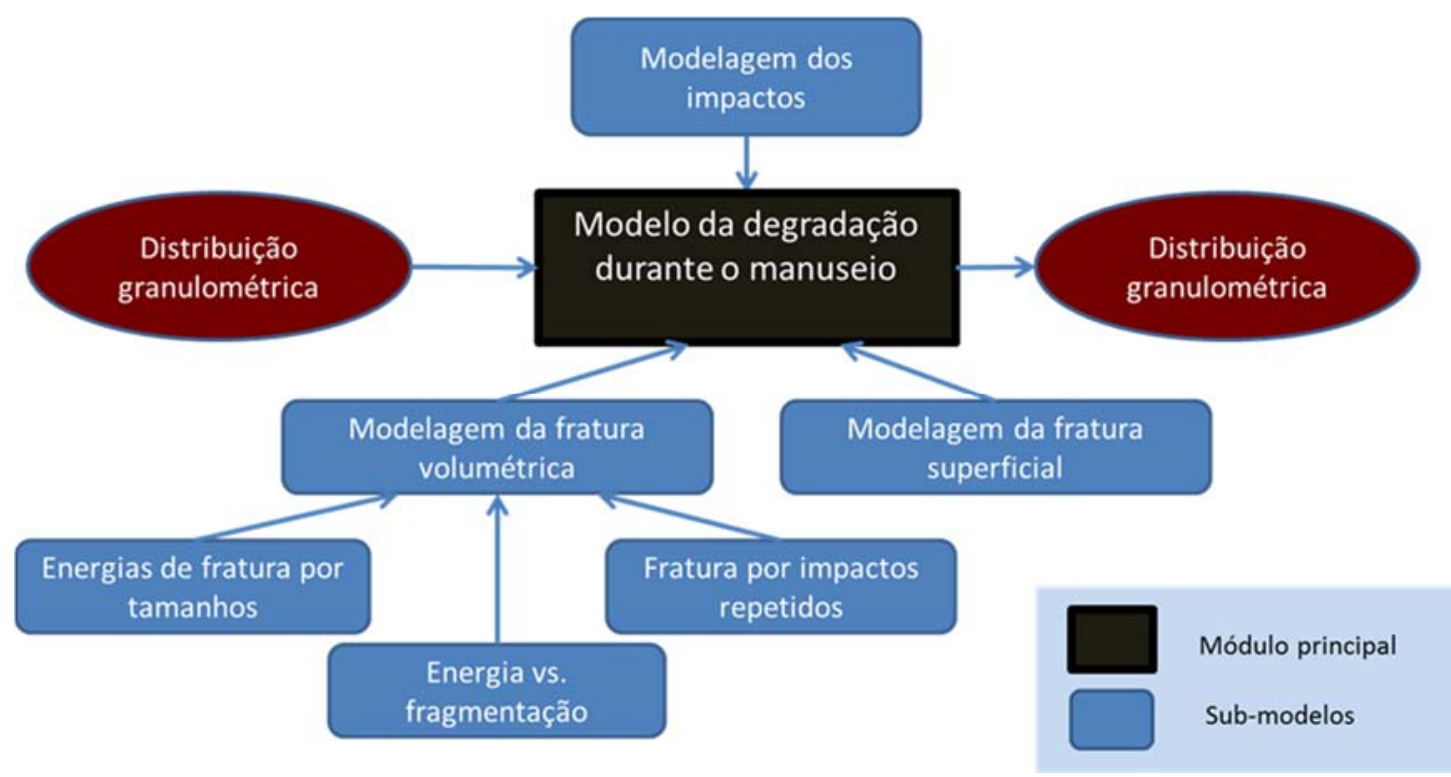

Figura 1. Esquema do modelo matemático da degradação

Inicial
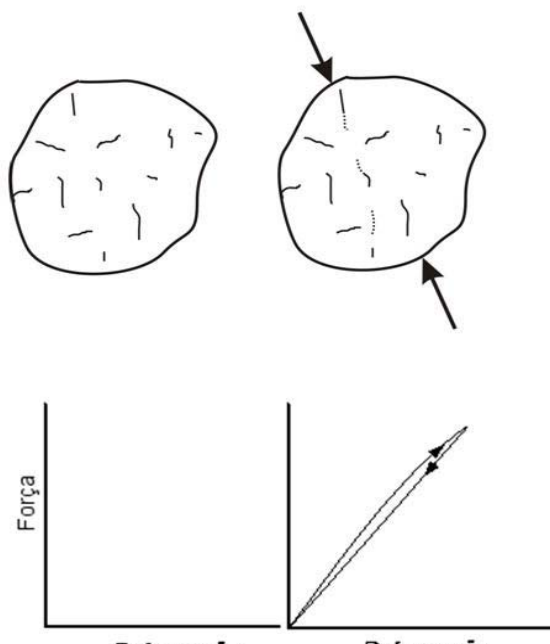

Deformaçāo $n=2$
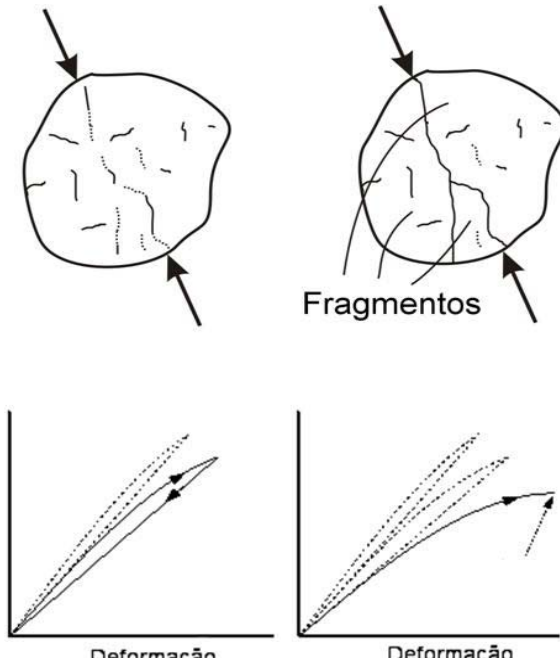

Figura 2. Ilustração do efeito de enfraquecimento devido ao acúmulo de dano causado por impactos repetidos de mesma energia [8]

O módulo principal do modelo (Figura 1) representa o sistema de equações de balanços de massas que permitem calcular a distribuição granulométrica do material oriundo de cada impacto, sendo dada por

$w_{i, n+1}=w_{i, n}\left[1-F_{i, n}\left(e E_{k, n}\right)\right]\left(1-\kappa_{j}\right)+\sum_{j=1}^{i} w_{j, n}\left[F_{j, n}\left(e E_{k, n}\right) b_{i j}+\kappa_{j}\left[1-F_{j, n}\left(e E_{k, n}\right)\right] a_{i j}\right]$

na qual $W_{i, n+1}$ e $w_{i, n}$ são as frações mássicas do material contido na classe de tamanhos $i$ antes e depois do $n$-ésimo impacto e e é a fração da energia de colisão 
que é capturada por uma partícula individual durante um impacto. $F_{i, n}\left(e E_{k}\right)$ é a probabilidade que uma partícula contida na classe de tamanhos $i$ irá quebrar quando capturada com uma energia $e E_{k}$ de uma queda. $\kappa_{i}$ é a taxa de abrasão das partículas contidas na classe de tamanhos $i$, a qual é presumida como independente da altura de queda, e $a_{i, j}$ é função quebra de abrasão (fragmentação superficial).

No modelo, a energia cinética de queda do n-ésimo impacto é estimada a partir de expressões analíticas da mecânica ou pelo uso do método dos elementos discretos (DEM) [7].

Os ensaios adotados nas diversas metodologias propostas de caracterização são resumidos na Tabela 1.

É importante reconhecer que o modelo discrimina entre pelotas bem formadas e pelotas mal formadas e cacos/fragmentos. Assim, ficou evidenciada a necessidade de reconhecer os seguintes aspectos na modelagem da degradação de pelotas e cacos:

- Uma proporção pequena, mas importante de cacos (fragmentos) se encontram no material que deixa o processo de produção e que é submetido às operações de manuseio.

- A distinção do fato que a fragmentação volumétrica de pelotas forma cacos e/ou finos, enquanto a fragmentação de cacos apenas forma cacos e/ou finos (Figura 3).

Tabela 1. Parâmetros e ensaios necessários para a calibração do modelo

\begin{tabular}{lcl}
\hline \multicolumn{1}{c}{ Ensaio } & Equipamento & \multicolumn{1}{c}{ Objetivo } \\
\hline $\begin{array}{l}\text { Energia de } \\
\text { fratura }\end{array}$ & $\begin{array}{c}\text { Célula de Carga } \\
\text { de Impacto }\end{array}$ & $\begin{array}{l}\text { Determinar a distribuição de energias de } \\
\text { fratura }\end{array}$ \\
\hline $\begin{array}{l}\text { Impactos } \\
\text { repetidos }\end{array}$ & $\begin{array}{c}\text { Drop weight } \\
\text { tester }\end{array}$ & $\begin{array}{l}\text { Determinar a resposta à fragmentação por } \\
\text { impactos repetidos }\end{array}$ \\
\hline $\begin{array}{l}\text { Fragmentação } \\
\text { volumétrica }\end{array}$ & $\begin{array}{c}\text { Drop weight } \\
\text { tester }\end{array}$ & $\begin{array}{l}\text { Determinar a distribuição de tamanhos em } \\
\text { função da energia aplicada }\end{array}$ \\
\hline $\begin{array}{l}\text { Fragmentação } \\
\text { superficial }\end{array}$ & $\begin{array}{l}\text { Fratura autógena } \\
\text { Determinar a proporção de finos gerada em } \\
\text { cada impacto de baixa magnitude }\end{array}$ \\
\hline
\end{tabular}

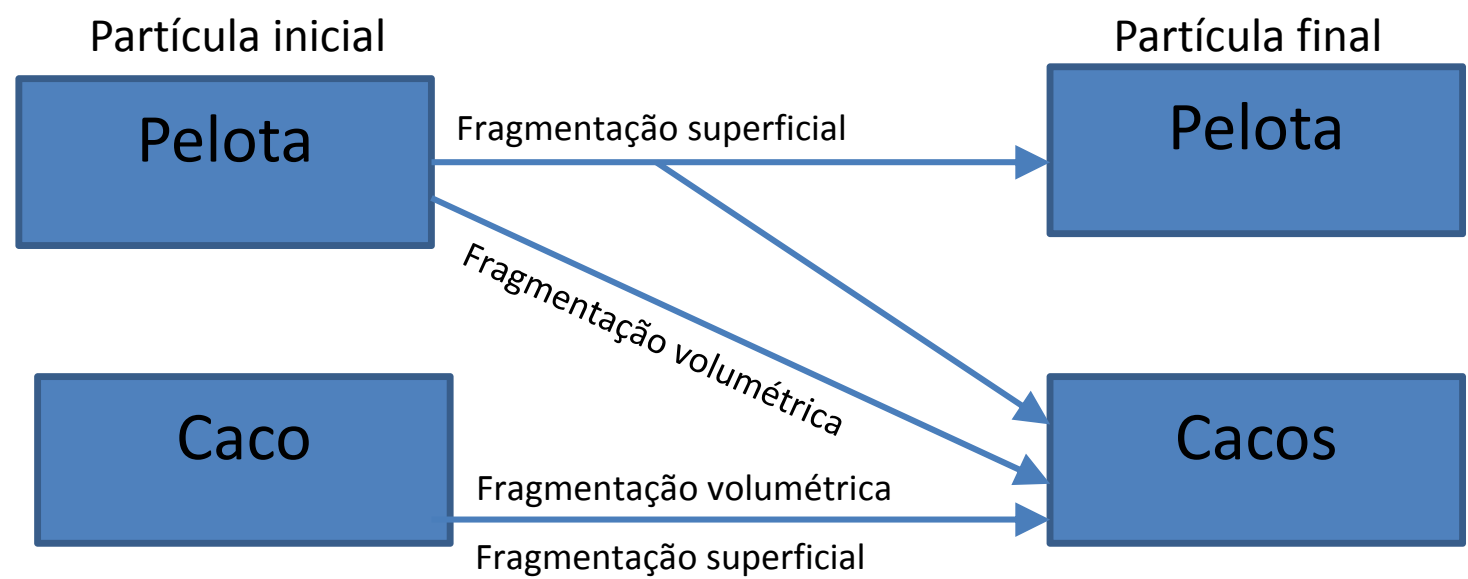

Figura 3. Esquema do modelo proposto para degradação de pelotas

A fim de viabilizar a utilização dos modelos matemáticos desenvolvidos dentro do presente estudo, tornando possível que engenheiros da empresa pudessem simular diferentes fluxogramas de manuseio com lotes de diferentes produtos, foi desenvolvido o simulador de manuseio em plataforma Matlab ${ }^{\circledR}$. A tela de entrada do 
simulador é apresentada na Figura 4, enquanto a Figura 5 mostra uma imagem do editor de fluxogramas.

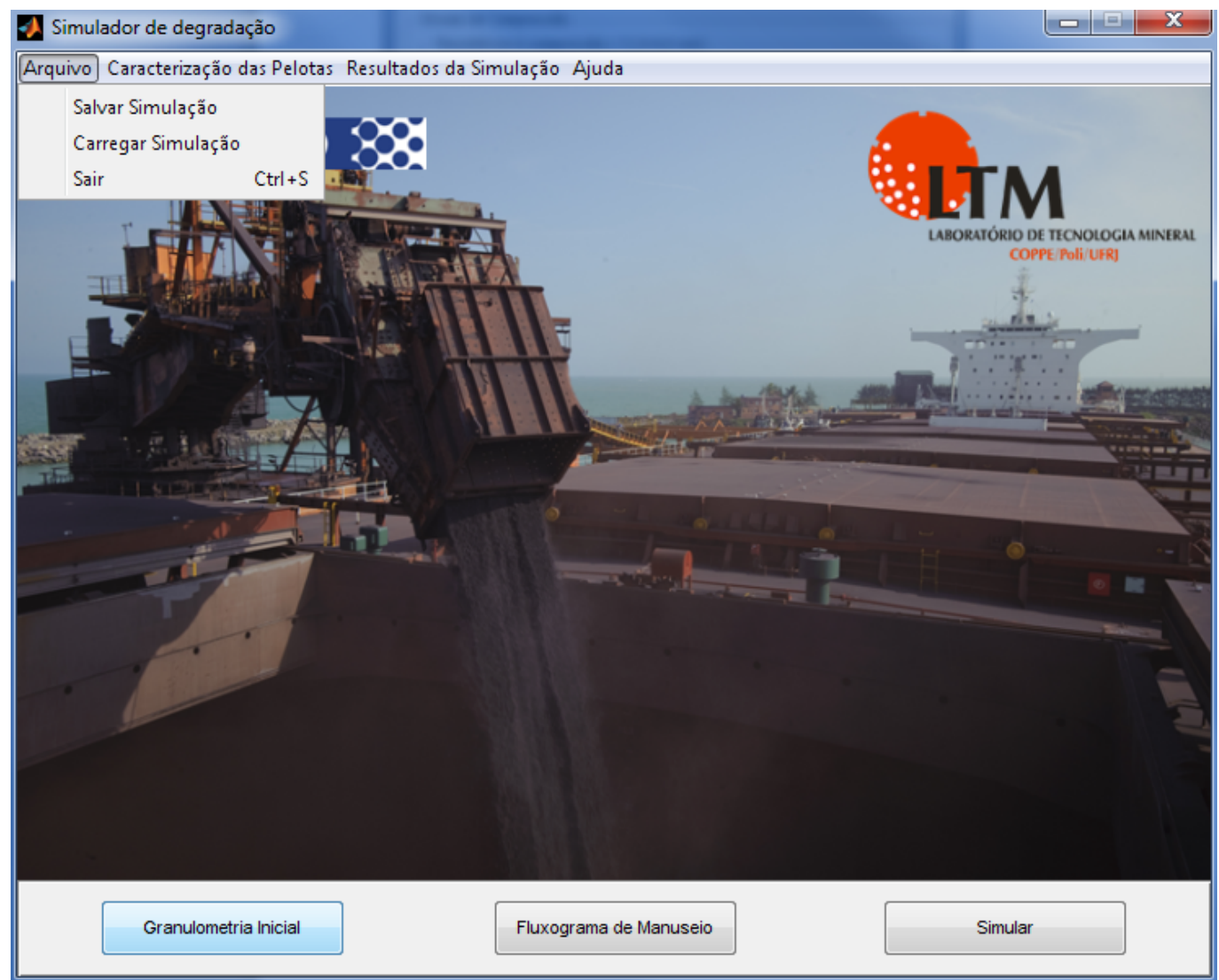

Figura 4. Tela de entrada do simulador de degradação

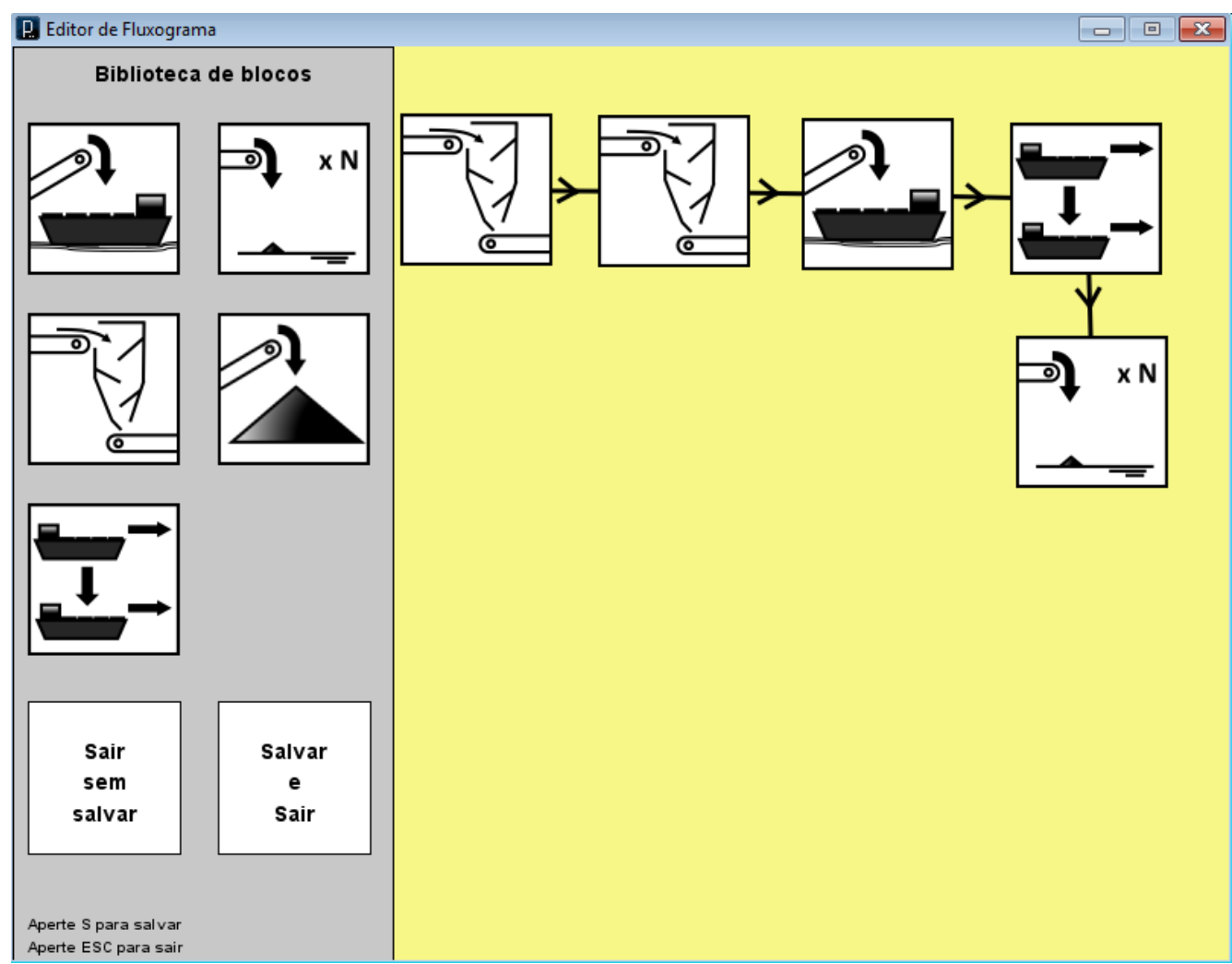

Figura 5. Imagem do editor de fluxogramas mostrando a biblioteca de ícones de operação prédefinidos (no lado esquerdo) e o fluxograma construído pelo usuário (lado direito) 
A capacidade do modelo de distinguir pelotas bem formadas de cacos permite prever resultados que discriminam a sua proporção em função da classe de tamanhos. Isso é ilustrado na Figura 6.

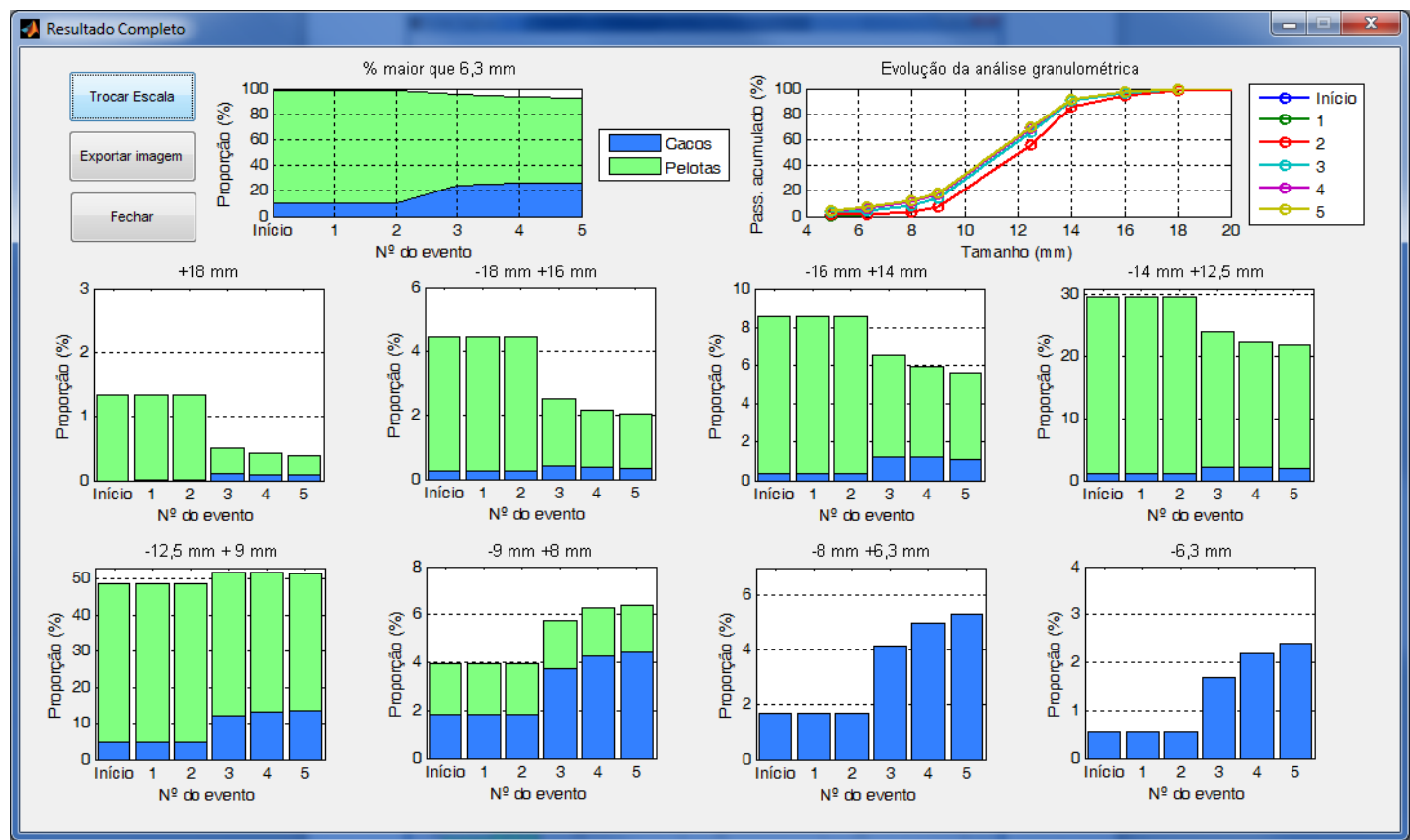

Figura 6. Janela do simulador, mostrando o resultado completo de uma simulação, identificando a proporção de pelotas bem formadas e cacos em função da etapa (evento) de manuseio por faixa de tamanhos

O carregamento da embarcação para o transporte transoceânico é uma etapa de importância central na degradação de pelotas. O simulador permite o detalhamento dos resultados, discriminando a geração de cacos em cada um dos porões da embarcação, que pode ser de três portes: menor 50 mil t, entre 50 a 100 mil t e maiores 100 mil t. Resultados típicos do simulador para o carregamento de uma embarcação são apresentados na Figura 7.

\section{MATERIAIS E MÉTODOS}

Amostras de pelotas da Samarco foram coletadas para ensaios. A amostra foi, inicialmente, fracionada por tamanhos, sendo medida a sua distribuição granulométrica, caracterizando a proporção de pelotas bem formadas e cacos por faixa de tamanhos. A amostra, contida em faixas estreitas de tamanhos, foi submetida aos ensaios listados na Tabela 1, permitindo determinar a distribuição de energias de fratura por impacto, bem como a resposta das pelotas à fragmentação superficial e volumétrica, em função da energia aplicada no impacto e do tamanho de partícula. Com isso, os sub-modelos (Figura 1) que compõem o modelo de degradação foram ajustados.

A fim de avaliar a capacidade do modelo de descrever a degradação de pelotas em uma operação típica de manuseio, um ensaio simples foi realizado, soltando-se um lote contendo $10 \mathrm{~kg}$ de pelotas a uma altura de $8,4 \mathrm{~m}$ contra uma placa de aço. Após cada colisão, a distribuição granulométrica do material era medida, sendo ainda medida a proporção de pelotas ainda íntegras e cacos. 


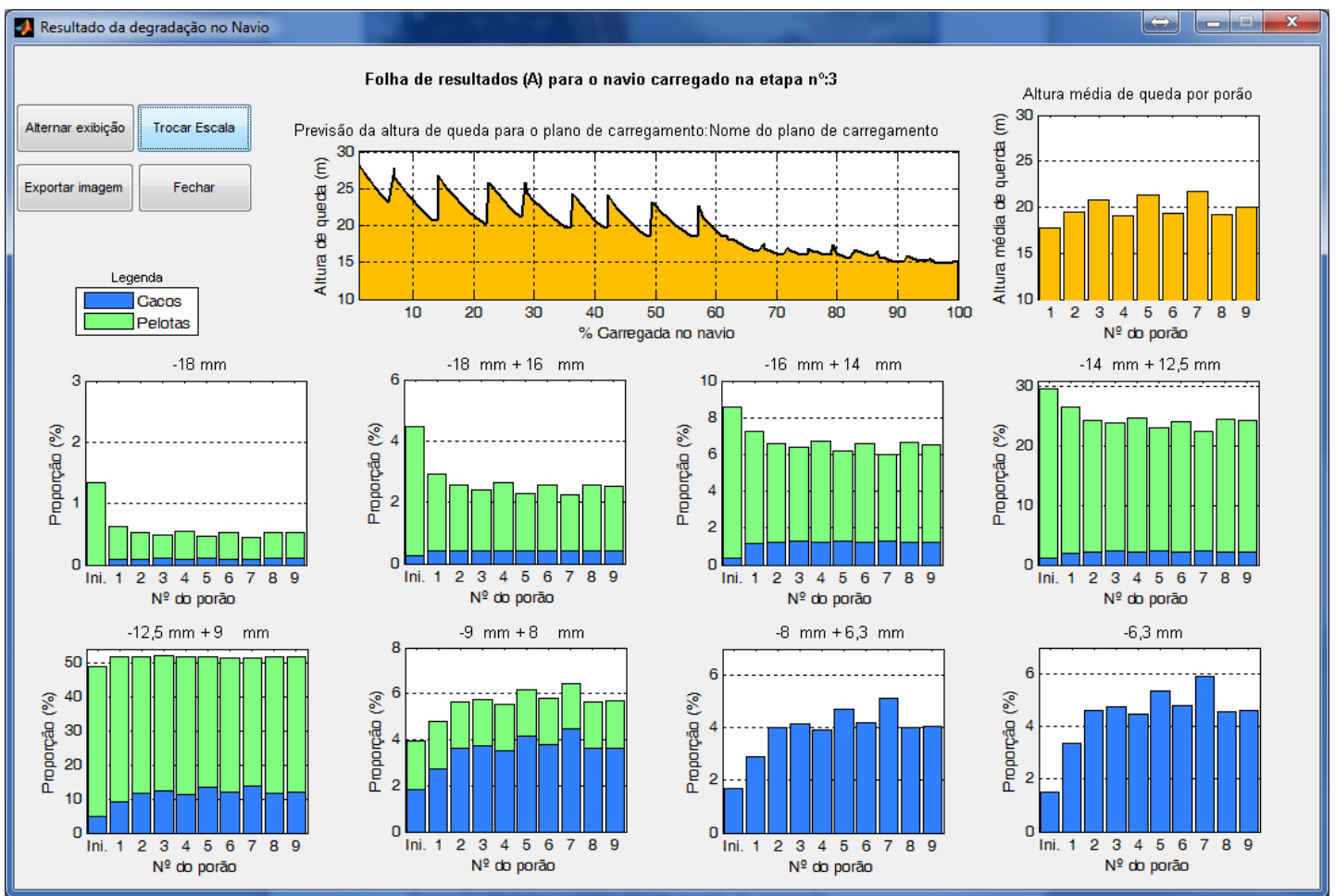

Figura 7. Janela do simulador, mostrando resultados da simulação de carregamento de embarcação, mostrando as proporções de pelotas e cacos

\section{RESULTADOS E DISCUSSÃO}

Resultados de ensaios realizados no sistema de queda livre foram comparados às previsões com o modelo, sendo os mesmos apresentados na Figura 8. A figura mostra que o modelo apresenta ótima aderência, sobretudo nas faixas extremas das distribuições granulométricas (acima de $10 \mathrm{~mm}$ e abaixo de $1 \mathrm{~mm}$ ). Isso é significativo, sobretudo tendo em vista que não foi realizado o ajuste do modelo de degradação aos resultados do ensaio de queda.

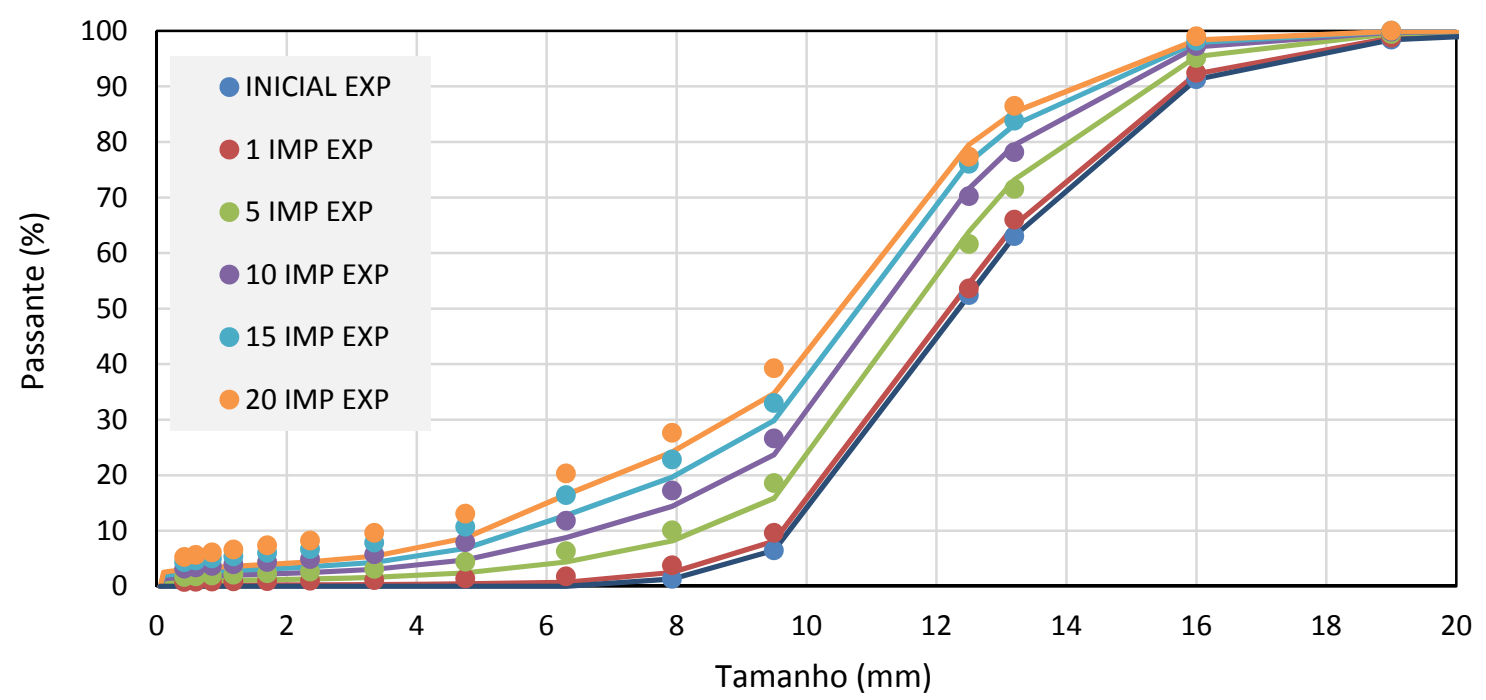

Figura 8. Comparação entre distribuições granulométricas simuladas (linhas) e dados experimentais (pontos) resultantes do ensaio de quedas múltiplas a partir de altura de $8,4 \mathrm{~m}$. 
A Figura 9 apresenta os resultados da simulação, mostrando a evolução da proporção de pelotas ainda íntegras e de cacos para as diferentes classes de tamanhos. Esse resultado é de grande relevância, tendo em vista a grande suscetibilidade dessas partículas à geração de clusters ou cachos em fornos de redução direta.

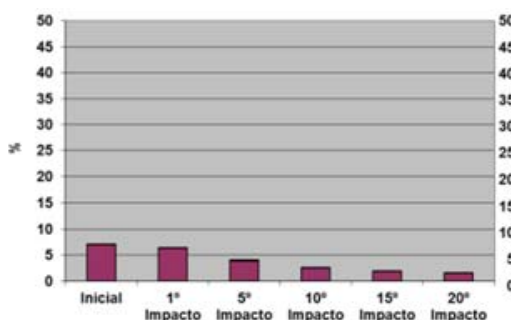

$19 \times 16 \mathrm{~mm}$

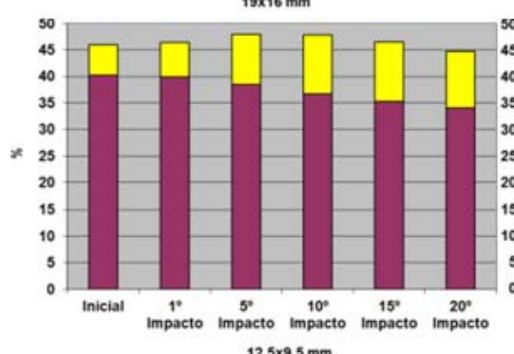

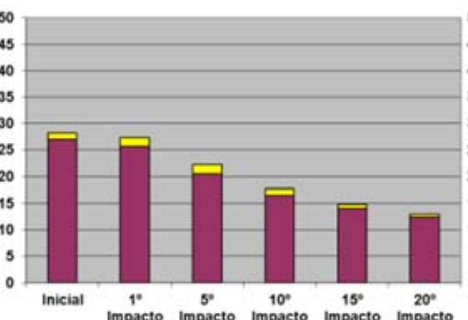
$16 \times 13,2 \mathrm{~mm}$

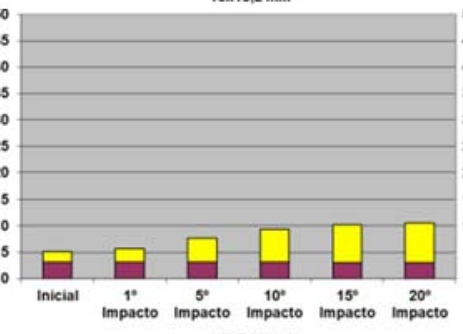

$9.5 \times 7,93 \mathrm{~mm}$

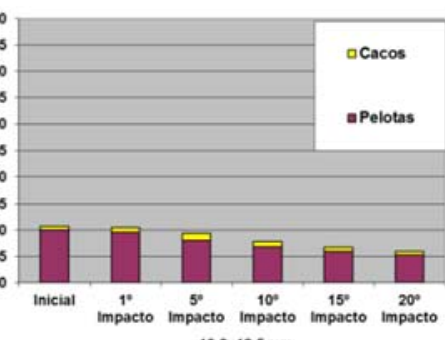

$13,2 \times 12,5 \mathrm{~mm}$

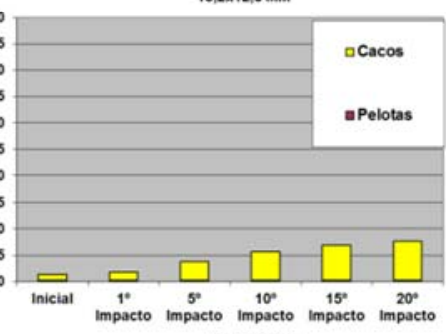

$7,93 \times 6,3 \mathrm{~mm}$

Figura 9. Evolução da distribuição de tamanhos do ensaio de transferência simulada utilizando o modelo.

Uma comparação consolidada da evolução da proporção (em massa) medida e prevista de pelotas é apresentada na Figura 10. Os resultados medidos sugerem que, da amostra inicialmente composta por, aproximadamente, $90 \%$ de pelotas, restam apenas $45 \%$ após 20 impactos, o que representa uma redução da ordem de $50 \%$ de pelotas. Os dados simulados mostram tendência semelhante, embora prevejam valores ainda menores de pelotas restantes.

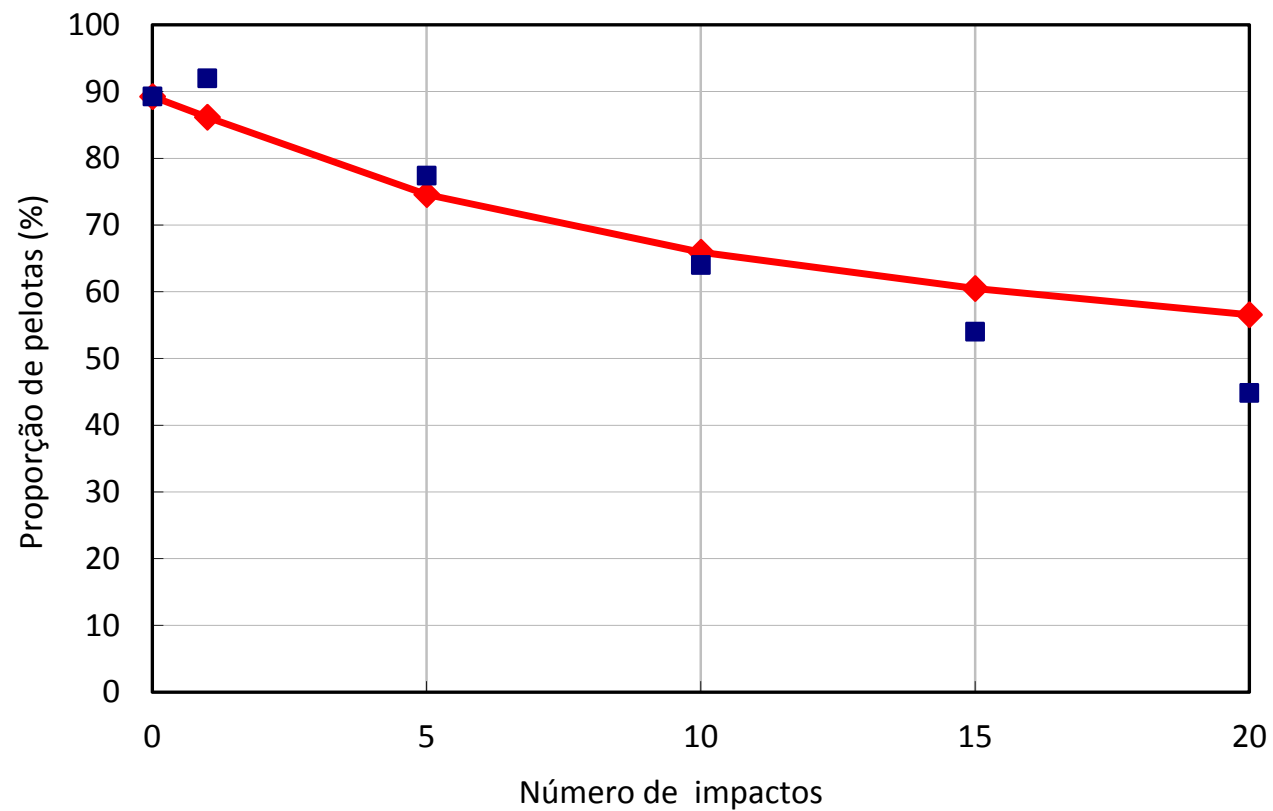

Figura 10. Variação da proporção de pelotas com o número de impactos no ensaio de queda em laboratório (azul: resultados medidos; vermelho: resultados simulados) 
caráter mecanicista do modelo permite inferir que o mesmo é capaz de prever resultados de colisões ou choques que pelotas são sujeitas durante as operações de manuseio e transporte, sobretudo no que diz respeito à influência das energias de colisão e dos tipos de superfícies de impacto.

\section{CONCLUSÃO}

Uma nova metodologia capaz de simular a degradação de pelotas durante o seu manuseio e transporte foi desenvolvida, que compreendeu a proposição de novas metodologias de caracterização da resistência de pelotas ao impacto, discriminando a fragmentação superficial (abrasão) da volumétrica, e de um modelo matemático da degradação. O modelo ainda leva em consideração a perda de resistência de pelotas quando submetidas a impactos sucessivos e a variabilidade da resistência de pelotas. Esse modelo foi utilizado em um simulador especificamente desenvolvido, que permitiu levar em consideração detalhes do fluxograma de manuseio.

\section{Agradecimentos}

Os autores agradecem à Samarco Mineração pelo financiamento da pesquisa e pela autorização para publicação do trabalho. Os autores da UFRJ agradecem ao CNPq pelas bolsas de estudos e pesquisa.

\section{REFERÊNCIAS}

1 Meyer, K. Pelletizing of iron ore. Berlin; New York: Springer-Verlag, 1980.

2 Pereira, J.G. Avaliação da utilização de diferentes materiais para diminuição da tendência de colagem de pelotas durante o processo de redução direta. Dissertação de Mestrado. Universidade Federal de Minas Gerais, Belo Horizonte, 2012.

3 Boechat, F.O. Simulação da degradação mecânica de pelotas de minério de ferro em fornos de redução direta usando o método dos elementos discretos. Dissertação de Mestrado, PEMM/COPPE. Universidade Federal do Rio de Janeiro, Rio de Janeiro, 2013.

4 Wright, J.K. The effect of firing conditions on the strength of hematite compacts. Powder Technology, 1976; 14: 103-113.

5 Fonseca, M. C. Influência da distribuição granulométrica do pellet feed no processo de aglomeração e na qualidade da pelota de minério de ferro para redução direta.

Dissertação de Mestrado. REDEMAT. Universidade Federal de Ouro Preto, Ouro Preto, 2004.

6 Costa, R. V. P. Otimização da resistência à compressão de pelotas de minério de ferro para redução direta pela aplicação de projeto robusto. Dissertação de Mestrado, REDEMAT, Universidade Federal de Ouro Preto, Ouro Preto.

7 Tavares, L.M., Carvalho, R.M. Modeling ore degradation during handling using continuum damage mechanics. International Journal of Mineral Processing. 2011; 101: 21-27.

8 Tavares, L.M. Analysis of particle fracture by repeated stressing as damage accumulation. Powder Technology. 2009; 190: 327-339. 